Chronic Obstructive Pulmonary Diseases: Journal of the COPD Foundation

\author{
Original Research
}

\title{
Effect of Triple Therapy with Budesonide-Formoterol-Tiotropium Versus Placebo-Tiotropium on Sleep Quality in Patients with Chronic Obstructive Pulmonary Disease
}

Samuel L. Krachman, DO ${ }^{1}$ Maria Elena Vega, MD $^{1}$ Daohai Yu, $\mathrm{PhD}^{2}$ Joseph Demidovich, DO ${ }^{1}$ Harsh Patel, $\mathrm{MD}^{1}$ Fredric Jaffe, DO ${ }^{1}$ Xavier Soler, MD ${ }^{3}$ Tahseen Shariff, RPSGT ${ }^{1}$ Gilbert E. D'Alonzo, DO ${ }^{1}$ Wissam Chatila, MD ${ }^{1}$ Sheila Weaver, DO ${ }^{1}$ Yasmin Daraz ${ }^{1 *}$ Sydney Cohen ${ }^{1 *}$ Gerard J. Criner, MD ${ }^{1}$

\section{Abstract}

Background: Factors responsible for poor sleep quality in patients with chronic obstructive pulmonary disease (COPD) includes the effects of medications. This study evaluates the effect of the inhaled triple therapy of budesonide-formoterol-tiotropium versus placebo-tiotropium on sleep quality in COPD patients.

Methods: Twenty-three patients (11 [48\%] males; age 55 [51-60, 48--5] years; body mass index [BMI] 25 [22$30,18-40] \mathrm{kg} / \mathrm{m}^{2}$; forced expiratory volume in 1 second [FEV $11.10[0.80-1.90,0.60-2.80] \mathrm{L}, 42$ [31-62, 24-75]\% predicted) were studied. Ten patients were randomized to budesonide-formoterol-tiotropium and 13 patients to placebo-tiotropium. At baseline and after 28 days, patients completed spirometry, polysomnography, an Epworth Sleepiness Scale (ESS), Pittsburgh Sleep Quality Index (PSQI), COPD-specific St George's Respiratory Questionnaire (SGRQ-C) and short form 36 (SF 36).

Results: After 28 days, there was a significant 29\% increase in the bedtime FEV 1 in the budesonide-formoteroltiotropium group (from 0.75 [0.55-1.30, 0.50-2.40]L to 1.00 [0.75-1.55, 0.50-3.00]L, $p=0.031$ ), with no change in the placebo-tiotropium group (from 1.20 [0.80-1.50, 0.60-1.90]L to 1.15 [0.75-1.55, 0.50-1.80]L, $p=0.91$ ). No significant change was found post treatment in sleep efficiency or total sleep time in both the budesonideformoterol-tiotropium group (from 78 [72-92, 62-98]\% to $88[77-92,40-98] \%, p=0.70$ and 290 [268-358, 252$382] \mathrm{min}$ to 342 [303-358, 157-372] min, $p=0.77$, respectively) and the placebo-tiotropium group (from 82 [75$88,46-93] \%$ to $84[77-87,62-94] \%, p=0.96$ and 320 [292-350, 180-378]min to 339 [303-349, 241-366]min, $p=0.79$, respectively). While there was no significant change in the arousal index in the budesonide-formoteroltiotropium group (9 [5-16, 0-48]arousals/hour to 14 [9-17, 2-36]arousals/hour, $p=0.43$ ), a significant increase was seen in the placebo-tiotropium group (11 [4-13,3--2]arousals/hour to 17 [11-21, 2-33]arousals/hour, $p=0.027$ ). Similarly, there was no change in the ESS in the budesonide-formoterol-tiotropium group (6 [3-8, $0-11]$ to $6[5-8,0-1]), p=0.44)$, but a marginally significant increase in the placebo-tiotropium group (8 [5$12,2-18]$ to 10 [7-13, 5-18], $p=0.07)$, with a significant difference in the ESS 28 days post treatment between the 2 groups ( $6[5-8,0-11]$ versus $10[7-13,5-18], p=0.043)$. There was no significant change in nocturnal oxygenation, sleep architecture, PSQI, SGRQ-C, or SF 36 in both groups.

Conclusion: In patients with COPD, inhaled triple therapy with budesonide-formoterol-tiotropium as compared to placebo-tiotropium improves pulmonary function while preserving sleep quality and architecture. 
Abbreviations: chronic obstructive pulmonary disease, COPD; forced expiratory volume in 1 second, FEV $\mathbf{1}$; body mass index, BMI; Epworth Sleepiness Scale, ESS; Pittsburgh Sleep Quality Index, PSQI; COPD-specific St George's Respiratory Questionnaire, SGRQ-C; short form 36, SF 36; rapid eye movement, REM; quality of life, QoL; obstructive sleep apnea, OSA; apnea-hypopnea index, AHI; standard deviation, SD; arterial oxygen saturation, $\mathrm{SaO}_{2}$

Funding Support: The study was supported by a grant from AstraZeneca.

Date of Acceptance: January 15, 2021 | Published Online Date: February 5, 2021

Citation: Krachman SL, Vega ME, Yu D, et al. Effect of triple therapy with budesonide-formoterol-tiotropium versus placebo-tiotropium on sleep quality in patients with chronic obstructive pulmonary disease. Chronic Obstr Pulm Dis. 2021;8(2):219-229. doi: https://doi. org/10.15326/jcopdf.2020.0178

1 Department of Thoracic Medicine and Surgery, Lewis Katz School of Medicine, Temple University, Philadelphia, Pennsylvania, United States

2 Department of Clinical Sciences, Temple Clinical Research Institute, Lewis Katz School of Medicine, Temple University, Philadelphia, Pennsylvania, United States

2 Department of Pulmonary, Critical Care, and Sleep Medicine, University of California, San Diego, California, United States * student

\section{Address correspondence to:}

Samuel L. Krachman, DO

Lewis Katz School of Medicine at Temple University

3401 North Broad St.

Philadelphia, PA 19140

Phone: (215) 707-4678

E-mail: samuel.krachman@tuhs.temple.edu

\section{Keywords:}

emphysema, COPD, sleep quality, nocturnal oxygen desaturation

\section{Introduction}

Sleep quality is known to be poor in patients with chronic obstructive pulmonary disease (COPD). Subjectively, patients complain of insomnia, with reported difficulty initiating sleep, nocturnal awakenings, daytime sleepiness and impaired daytime concentration. ${ }^{1-6}$ Insomnia complaints appear to be more prevalent in those patients with associated daytime symptoms of cough, dyspnea, and wheezing. ${ }^{2,3}$ Objectively, poor sleep quality has been demonstrated, with an increased sleep latency, decreased total sleep time, increased arousal index, and decrease in N3 and rapid eye movement (REM) sleep. ${ }^{7-10}$ Disturbed sleep appears to be an important factor for the decrease in the quality of life (QoL) reported by these patients. ${ }^{6,11}$ In addition, disrupted sleep has been shown to be a predictor of COPD exacerbation rate and overall survival. ${ }^{12}$

Several factors have been suggested to be responsible for the poor sleep quality seen in patients with COPD. One is the development of nocturnal hypoxemia, which can occur despite the presence of an awake partial pressure of oxygen $\left(\mathrm{PaO}_{2}\right)>60$ mmHg. ${ }^{13,14}$ An association between nocturnal hypoxemia and objective assessment of sleep quality has been reported. ${ }^{1,10}$ Sympathetic activity, which is increased with chronic hypoxemia, may contribute to the disturbed sleep in these patients. ${ }^{15,16}$ While the effects of oxygen therapy on sleep quality have been variable $7,8,17,18$ some studies have demonstrated improved sleep quality ${ }^{7,18}$ which may be related to a decrease in sympathetic activity. ${ }^{19}$

Poor sleep quality may also be related to the abnormal respiratory mechanics and increased work of breathing in COPD patients. ${ }^{10,20-22}$ Parameters of respiratory function and mechanics have been shown to predict sleep quality in these patients, as assessed quantitatively by polysomnography. ${ }^{10,22}$ Therapies that have been demonstrated to improve respiratory mechanics have been associated with an improvement in sleep quality. ${ }^{20,21}$ The improvement in sleep quality was seen despite the absence of an associated improvement in nocturnal oxygenation. ${ }^{21}$

There are several medications used in the treatment of COPD that may affect sleep quality. Results have beenvariable, with some demonstrating either no effect or a worsening in sleep quality. ${ }^{23-31}$ In addition, there have been studies demonstrating an improvement in sleep quality, often associated with improvements in both nocturnal oxygenation and respiratory mechanics. 6 Included were studies examining the effects of long-acting beta2-agonists and long-acting anticholinergics. ${ }^{6}$ More recently, triple therapy, which includes an inhaled corticosteroid, long-acting beta2-agonist and long-acting anticholinergic, has been shown to improve airway function, decrease exacerbations, and improve QoL when compared to dual or single therapy in patients with COPD. ${ }^{33-42}$ However, the effect of triple therapy on sleep quality 
has not been previously studied in these patients. We hypothesized that triple therapy consisting of budesonide-formoterol-tiotropium would improve sleep quality as compared to placebo-tiotropium alone in patients with Global initiative for chronic Obstructive Lung Disease (GOLD) ${ }^{43}$ stage 2 and 3 COPD, possibly by improving nocturnal oxygenation and respiratory mechanics during sleep.

\section{Methods}

\section{Patient Selection}

Twenty-five consecutive patients with GOLD stage 2 and 3 COPD were recruited from the Pulmonary Clinic at Temple University Hospital to participate in the study. All of the patients were already on a bronchodilator regimen when they were asked to participate. Patients were excluded from the study if: (1) they required supplemental oxygen; (2) they had a COPD exacerbation within the past 4 weeks; (3) they had a previous diagnosis of obstructive sleep apnea (OSA) (apnea-hypopnea index [AHI]>10 events/hour); (4) they were taking an oral steroid medication; (5) there was a known history of urinary outflow obstruction, glaucoma, or a history of an allergic reaction to one of the study medications; and (6) they had a positive pregnancy test (in women of child-bearing age). Patients were also excluded if they were not willing to participate in all aspects of the study, including an overnight polysomnogram, or were not willing to sign informed consent. The study was approved by the Lewis Katz School of Medicine at Temple University Institutional Review Board for Human Research (Philadelphia, Pennsylvania).

\section{Polysomnograms}

Polysomnograms were performed while breathing room air, following the American Academy of Sleep Medicine Guidelines. ${ }^{44}$ Sleep was staged and arousals defined using established criteria. ${ }^{33}$ Obstructive apneas were defined by the lack of airflow for greater than 10 seconds, associated with the presence of rib cage and abdominal movement. ${ }^{44}$ Obstructive hypopneas were defined by a 30\% decrease in airflow for greater than 10 seconds, associated with the presence of rib cage and abdominal movement, and accompanied by an oxygen desaturation of $>3 \%$ or an arousal. ${ }^{44}$ Apneas were defined as central if there was a lack of respiratory effort during the period of absent airflow. ${ }^{44}$ The AHI was calculated as the number of apneic and hypopnic events per hour of sleep. Sleep efficiency was defined as the total sleep time/ time in bed (\%). All of the polysomnogram studies were initially scored by a single senior technologist. The same author (SK) reviewed each study.

\section{Spirometry}

All spirometry was performed using the EasyOne spirometer (ndd Medical, Zurich, Switzerland) in accordance with American Thoracic Society/ European Respiratory Society recommendations. ${ }^{34}$ The largest forced expiratory volume in 1 second $\left(F E V_{1}\right)$ and forced vital capacity (FVC) from 3 acceptable maneuvers were utilized even if they were from different forced expiratory curves. ${ }^{45}$

\section{Questionnaires}

Subjective daytime sleepiness was assessed using the Epworth Sleepiness Scale (ESS). ${ }^{46}$ The Pittsburgh Sleep Quality Index (PSQI) assesses sleep quality and disturbances over a 1-month time interval. ${ }^{47}$ The COPD-specific version of the St George's Respiratory Questionnaire (SGRQ-C) was completed to assess disease specific impact to overall quality of life ${ }^{48}$ and the short form 36 (SF 36) health survey questionnaire was completed to evaluate overall health status. ${ }^{49}$

\section{Protocol}

Patients underwent an acquaintance night polysomnogram to account for a "first night" effect of sleeping in a new environment. Patients were then asked to stop using any long-acting beta2-agonists or long-acting muscarinic antagonists and instructed to just use albuterol as needed until they returned after 2 weeks for a baseline polysomnogram study. Following the baseline polysomnogram, study patients were randomized to 1 of 2 groups: (1) budesonide-formoterol $160 \mathrm{mcg} / 4.5 \mathrm{mcg}-\mathrm{AM}$ and $\mathrm{PM}+$ tiotropium $18 \mathrm{mcg}-\mathrm{AM}$ or (2) placebo - AM and $\mathrm{PM}+$ tiotropium $18 \mathrm{mcg}-\mathrm{AM}$. The investigators were blinded to which group the patients were randomized. Randomization allocations were performed with a random number generator, using permuted blocks of 6. Patients then returned for a final polysomnogram study at the end of 28 days. Prior to the baseline and final polysomnogram studies, patients completed the questionnaires and spirometry was performed prior to sleep onset in the sleep lab. During the 28 days 
of the study, patients recorded their daily usage of albuterol required for rescue therapy.

\section{Statistical Analysis}

The data are presented as the median (interquartile range, range). Comparison of baseline data between the budesonide-formoterol-tiotropium and placebotiotropium groups was done using exact Wilcoxon rank-sums tests. Sign rank tests were used to evaluate the changes at 28 days post treatment in each of the groups. The Fisher Exact Test was performed to compare proportions between groups. No regression was conducted due to the small group sizes. The relationship between changes in spirometry values and sleep parameters were assessed by Spearman correlation coefficients. The sample size was estimated based on our previous study evaluating the effects of noninvasive ventilation on sleep quality in COPD. ${ }^{21}$ In that study, we noted a $20 \%+5 \%$ standard deviation (SD) increase in sleep efficiency with therapy. Using a similar increase in sleep efficiency, we calculated that we would need 10 patients in each group to achieve a $100 \%$ power to detect a similar change in sleep efficiency in those patients receiving budesonide-formoterol-tiotropium. Even using a more conservative change of $10 \%+10 \%$ would give a $90 \%$ power to detect this change with 10 patients in each group at an alpha of 0.05. All statistical analyses were performed using a commercially available computer software program (SAS version 9.4, SAS Institute Inc., Cary, North Carolina); $p<0.05$ was considered statistically significant.

\section{Results}

\section{Patient Characteristics}

Twenty-three patients (11 [48\%] males; age 55 [51-60, 48-75] years; body mass index [BMI] 25 [22-30, $18-40] \mathrm{kg} / \mathrm{m}^{2} ; \mathrm{FEV}_{1} 1.10$ [0.80-1.90, 0.60-2.80]L, 42 [31-62, 24-75]\% predicted) were enrolled and completed the study. Two patients were enrolled but did not complete the study; both refused to undergo the final polysomnogram. Ten patients (6 [60\%]males; age 59 [54-64, 50-70]years; BMI $25[20-30,18-32] \mathrm{kg} / \mathrm{m}^{2} ; \mathrm{FEV}_{1} 1.05$ [0.8-1.10,0.70-2.80]L, 38 [30-65, 24-74]\% predicted) were randomized to the budesonide-formoterol-tiotropium group and 13 patients (5 [39\%] males; age 52 [51-56, 48-75]years;
BMI 26 [22-30, 22-40] kg/m²; FEV 1.20 [0.80-1.90, $0.60-2.40] \mathrm{L}, 49[35-58,30-75] \%$ predicted) were randomized to the placebo-tiotropium group, with no significant clinical difference between the 2 groups (Table 1).

\section{Effects on Airflow Obstruction}

At the end of 28 days there was a significant 29\% increase in the bedtime $\mathrm{FEV}_{1}$ in the budesonideformoterol-tiotropium group (from 0.75 [0.55-1.30, $0.50-2.40] \mathrm{L}$ to $1.00 \quad[0.75-1.55,0.50-3.00] \mathrm{L}$, $p=0.031$ ), with no significant change noted in the placebo-tiotropium group (from 1.20 $[0.80-1.50,0.60-1.90] \mathrm{L}$ to 1.15 [0.75-1.55, $0.50-1.80] \mathrm{L}, p=0.91$ ) and a significant difference in the change in bedtime FEV 28 days post treatment between the 2 groups (0.20 [0.10-0.45, $-0.10-0.60] \mathrm{L}$ versus -0.05 [-0.20-0.10,-0.30-0.30]L, $p=0.026$ ) (Table 2). There was a similar significant increase in the bedtime $\mathrm{FEV}_{1} \%$ predicted in the budesonide-formoterol-tiotropium group (from 29 [23-37, 22-62]\% predicted to 38 [31-48, 25-79]\% predicted, $p=0.039)$ with no significant change noted in the placebo-tiotropium group (from 46 [42-49, $27-60] \%$ predicted to $48[38-57,19-71] \%$ predicted, $p=0.81$ ), with a marginally significant difference in the change in bedtime $\mathrm{FEV}_{1} \%$ predicted 28 days post treatment between the 2 groups (7 [3-14, -3-26]\% predicted versus -1 (-6-9, -12-15)\% predicted, $p=0.086$ ) (Table 2).

\section{Effects on Sleep Quality}

There was no significant change in sleep efficiency at the end of 28 days in the budesonide-formoteroltiotropium group (from 78 [72-92, 62-98]\% to $88[77-92,40-98] \%, p=0.70)$ and in the placebotiotropium group (from 82 [75-88, 46-93]\% to $84[77-87,62-94] \%, p=0.96)$. In addition, the total sleep time did not change significantly at the end of 28 days in the budesonide-formoterol-tiotropium group (from $290[268-358,252-382]$ minutes to $342[303-358,157-372]$ minutes, $p=0.77$ ) and in the placebo-tiotropium group (from 320 [292-350, 180-378] minutes to 339 [303-349, 241-366] minutes, $p=0.79$ ). While there was no significant change in the arousal index in the budesonideformoterol-tiotropium group (from 9 [5 -16, 0-48] arousals/hour to 14 (9-17, 2-36)arousals/hour, $p=0.43$ ), there was a significant increase seen in the 


\section{Table 1. Baseline Characteristics}

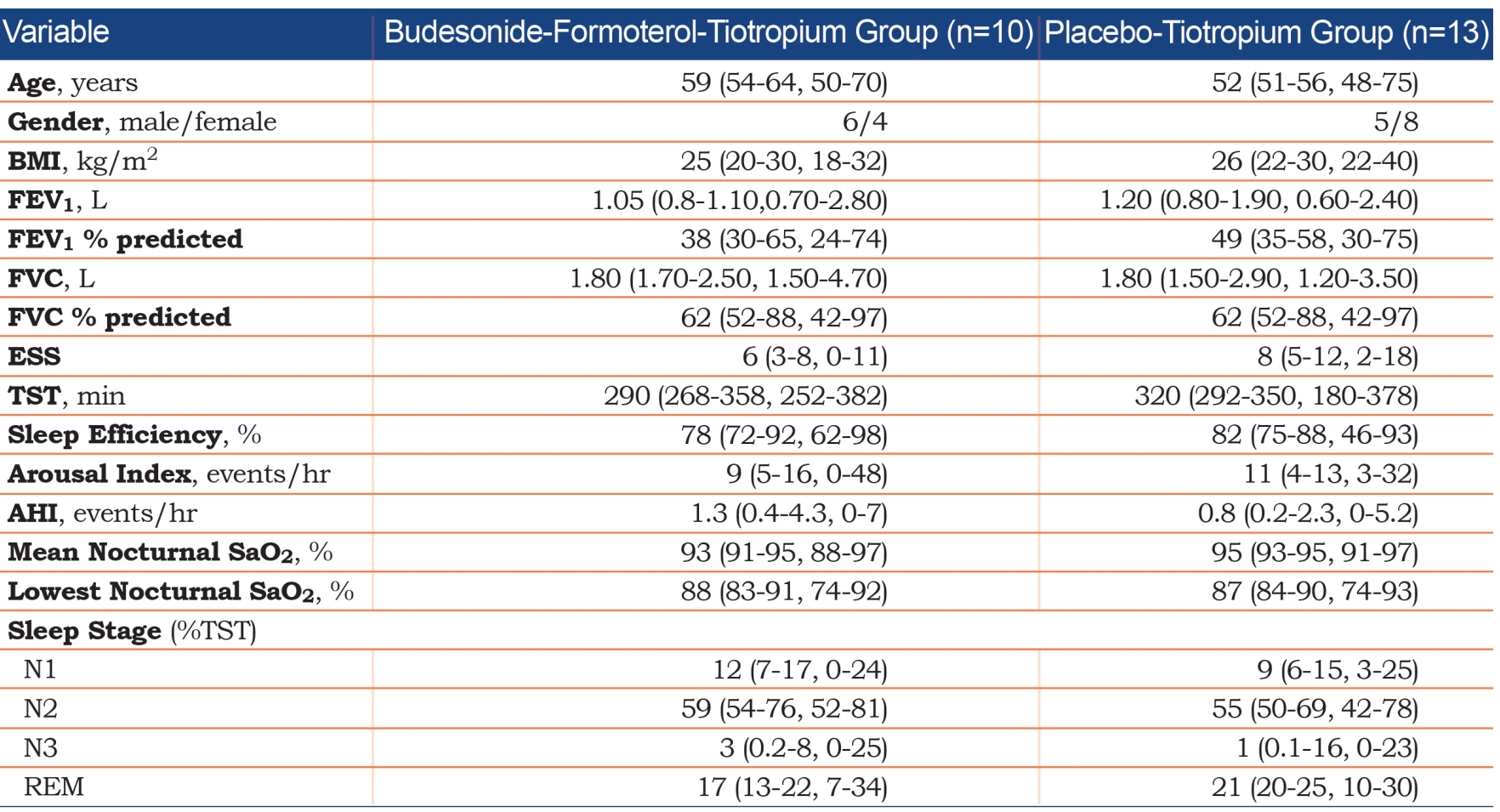

$\mathrm{BMI}=$ body mass index; $\mathrm{FEV}_{1}=$ forced expiratory volume in 1 second; $\mathrm{FVC}=$ forced vital capacity; ESS=Epworth Sleepiness Scale; TST=total sleep time; $\mathrm{AHI}=$ apnea-hypopnea index; $\mathrm{SaO}_{2}$ oxygen saturation; $\mathrm{REM}=$ rapid eye movement.

placebo-tiotropium group (from 11 [4-13, 3-32] arousals/hour to 17 [11-21, 2-33]arousals/hour, $p=0.027$ ) (Table 2).

At the end of 28 days there was no significant change in the PSQI in the budesonide-formoteroltiotropium group (from $7[6-10,4-15]$ to 6 [6-11, 4-15], $p=0.53$ ) and the placebo-tiotropium group (from $9[9-11,4-18]$ to 9 [9-11, 4-18], $p=0.19$ ). However, while there was no significant change in the ESS seen in the budesonide-formoterol-tiotropium group (from $6[3-8,0-11]$ to $6[5-8,0-11], p=0.44$ ), there was a marginally significant increase in the placebo-tiotropium group (from 8 [5-12, 2-18] to $10[7-13,5-18], p=0.07$ ), with a significant difference in the ESS between the 2 groups at the end of the 28 days (6 [5-8, 0-11] versus 10 [7-13, 5-18], $p=0.043$ ). There was no significant change in sleep architecture noted at the end of 28 days in both the budesonideformoterol-tiotropium group and placebo-tiotropium group (Table 2).

\section{Nocturnal Oxygenation and Sleep-Disordered Breathing}

At the end of 28 days, there was no significant change in the budesonide-formoterol-tiotropium group and the placebo-tiotropium group in the mean oxygen saturation during the night (93 $[91-95,88-97] \%$ to $93[91-94,88-97] \%, p=0.50$, and $95[93-95,91-97] \%$ to $93[91-94,88-97] \%$, $p=0.73$, respectively), the lowest oxygen saturation during the night (88 [83-91, 74-92]\% to 87 [81-89, $78-92] \%, \quad p=0.80$, and $87 \quad[84-90,74-93] \%$ to $87[86-90,84-97] \% p=0.18$, respectively), and the $\%$ total sleep time with an arterial oxygen saturation $\left(\mathrm{SaO}_{2}\right)<90 \%(1.4[0-18.2,0-83.9] \%$ to 0.95 [0.6-14.5, $0-77.7] \%, p=0.30$, and $1.3[0-6.1,0-21.1] \%$ to 0.40 [0-5.7, 0-12.4]\%, $p=0.46$, respectively). The AHI did not change in both the budesonideformoterol-tiotropium group (1.3 [0.4-4.3, 0-7] events/hour to $0.9[0-2.6,0-8.2]$ events/hour, $p=0.49$ ) and the placebo-tiotropium group (0.8 $[0.2-2.3,0-5.2]$ events/hour to 0.5 [0-2.1, 0-15.9] events/hour, $p=0.88$ ) at the end of 28 days.

\section{Quality of Life}

There was no significant change at the end of 28 days in the budesonide-formoterol-tiotropium group and the placebo-tiotropium group for both the SGRQ-C (54 [42-60, 32-75] to 50 [42-51, 18-63], $p=0.48$, and $41[27-61,17-71]$ to $44 \pm 14, p=0.70$, 


\begin{tabular}{|c|c|c|c|}
\hline \multirow[t]{2}{*}{ Variable } & Baseline & 28 Days & \multirow[t]{2}{*}{$P$ Value } \\
\hline & \multicolumn{2}{|c|}{ Budesonide-Formoterol-Tiotropium } & \\
\hline $\mathbf{F E V}_{1}, \mathrm{~L}$ & $0.75(0.55-1.30,0.50-2.40)$ & $1.00(0.75-1.55,0.50-3.00)$ & $0.031^{\mathrm{a}}$ \\
\hline FEV $_{1} \%$ predicted & $29(23-37,22-62)$ & $38(31-48,25-79)$ & $0.039^{\mathrm{a}}$ \\
\hline ESS & $6(3-8,0-11)$ & $6(5-8,0-11)$ & 0.440 \\
\hline PSQI & $7(6-10,4-15)$ & $6(6-11,4-15)$ & 0.530 \\
\hline TST, min & $290(268-358,252-382)$ & $342(303-358,157-372)$ & 0.770 \\
\hline Sleep Efficiency, $\%$ & $78(72-92,62-98)$ & $88(77-92,40-98)$ & 0.700 \\
\hline Arousal Index, events/hr & $9(5-16,0-48)$ & $14(9-17,2-36)$ & 0.430 \\
\hline Mean Nocturnal $\mathbf{S a O}_{2}, \%$ & $93(91-95,88-97)$ & $93(91-94,88-97)$ & 0.500 \\
\hline Lowest Nocturnal $\mathrm{SaO}_{2}, \%$ & $88(83-91,74-92)$ & $87(81-89,78-92)$ & 0.800 \\
\hline \multicolumn{4}{|l|}{ Sleep Stage (\%TST) } \\
\hline N1 & $12(7-17,0-24)$ & $8(5-13,4-30)$ & 0.810 \\
\hline N2 & $59(54-76,52-81)$ & $61(47-74,39-80)$ & 0.570 \\
\hline N3 & $3(0.2-8,0-25)$ & $2(0-11,0-32)$ & 0.630 \\
\hline \multirow[t]{2}{*}{ REM } & $17(13-22,7-34)$ & $20(15-23,11-32)$ & 0.260 \\
\hline & \multicolumn{2}{|c|}{ Placebo-Tiotropium Group } & \\
\hline $\mathbf{F E V}_{1}, \mathrm{~L}$ & $1.20(0.80-1.50,0.60-1.90)$ & $1.15(0.75-1.55,0.50-1.80)$ & 0.910 \\
\hline FEV $_{1} \%$ predicted & $46(42-49,27-60)$ & $48(38-57,19-71)$ & 0.810 \\
\hline ESS & $8(5-12,2-18)$ & $10(7-13,5-18)$ & 0.070 \\
\hline PSQI & $9(9-11,4-18)$ & $9(9-11,4-18)$ & 0.190 \\
\hline TST, min & $320(292-350,180-378)$ & 339 (303-349, 241-366) & 0.790 \\
\hline Sleep Efficiency, $\%$ & $82(75-88,46-93)$ & $84(77-87,62-94)$ & 0.960 \\
\hline Arousal Index, events/hr & $11(4-13,3-32)$ & $17(11-21,2-33)$ & $0.027^{\mathrm{a}}$ \\
\hline Mean Nocturnal SaO $\mathbf{S a}_{2}, \%$ & $95(93-95,91-97)$ & $93(91-94,88-97)$ & 0.730 \\
\hline Lowest Nocturnal $\mathrm{SaO}_{2}, \%$ & $87(84-90,74-93)$ & $87(86-90,84-97)$ & 0.180 \\
\hline \multicolumn{4}{|l|}{ Sleep Stage (\%TST) } \\
\hline $\mathrm{N} 1$ & $9(6-15,3-25)$ & $9(5-14,2-22)$ & 0.610 \\
\hline $\mathrm{N} 2$ & $55(50-69,42-78)$ & $65(55-70,51-80)$ & 0.190 \\
\hline N3 & $1(0-16,0-23)$ & $2(0-4,0-26)$ & 0.130 \\
\hline REM & $21(20-25,10-30)$ & $22(15-26,3-34)$ & 0.780 \\
\hline
\end{tabular}

$\mathrm{FEV}_{1}=$ forced expiratory volume in 1 second; ESS=Epworth Sleepiness Scale; PSQI=Pittsburgh Sleep Quality Index; TST=total sleep time; $\mathrm{SaO}_{2}=$ oxygen saturation; $\mathrm{REM}=$ rapid eye movement

respectively) and the SF 36 for physical functioning (45 [33-68, 20-100] to 45 [33-61, 15-95], $p=0.66$, and $45[30-68,10-90]$ to $40 \quad[30-65$, 5-85], $p=0.77$, respectively) and the SF 36 for emotional well-being (76 [50-85, 40-96] to 86 [58-93, 28-96], $p=0.21$, and $68[46-84,32-92]$ to 60 [36-82, 20-100], $p=0.19$, respectively).

\section{Discussion}

Patients with COPD often report poor sleep quality, which can affect daytime function and overall quality of life. ${ }^{1-6,11}$ Disrupted sleep is noted even in those patients in whom associated OSA (OSACOPD overlap syndrome) has been excluded. ${ }^{10,20}$ Many factors have been suggested to be responsible for the poor sleep quality in these patients including nocturnal hypoxemia, abnormalities in respiratory mechanics, and the effects of prescribed medications. ${ }^{1,6,10,22-32}$ In regards to bronchodilator therapy, these studies have involved examining the effects of individual medications on sleep quality. In patients with severe underlying COPD, combinations of bronchodilators are more commonly used, with 
recent studies demonstrating improved lung function, reduced exacerbation rates, and hospitalizations in those patients receiving triple therapy (inhaled corticosteroid, long-acting beta2-agonist, and longacting anticholinergic) as opposed to single or dual therapy. ${ }^{33-42}$ However, no previous study has examined the effects of triple therapy on sleep quality.

There are 2 major findings in this study: (1) at the end of 28 days, airflow obstruction significantly improved in the budesonide-formoterol-tiotropium group but not in the placebo-tiotropium group; and (2) the improvement in spirometry in the budesonideformoterol-tiotropium group did not have a negative effect on quantitative and subjective measurements of sleep quality, nocturnal oxygenation, or subjective measurement of daytime function.

Poor sleep quality in patients with COPD is prevalent and associated with overall QoL. 5,6,11,12 Budhiraja et $\mathrm{al}^{6}$ reported insomnia to be present in $27.3 \%$ of COPD patients, with an associated lower QoL score as compared to those without insomnia. Nunes et $\mathrm{ll}^{11}$ found poor sleep quality, as determined by PSQI, to be the best predictor of QoL in 30 patients with GOLD stage 2-4 COPD. Omachi et al ${ }^{12}$ demonstrated that disturbed sleep predicted both the incidence of COPD exacerbations and poorer survival. Our patients had similar baseline characteristics both in the severity of their obstructive disease as well as in measurements of sleep quality and QoL.

With regard to the effects of bronchodilator medications on sleep quality in patients with COPD, the results have been variable. Ryan et al ${ }^{31}$ studied the effects of the long-acting beta2-agonist salmeterol on sleep quality and nocturnal oxygenation in 12 patients with COPD. Compared to placebo at the end of 4 weeks, there was an increase in the mean $\mathrm{SaO}_{2}$ during the night but no change in sleep quality as assessed by polysomnogram. However, it should be noted that compared to placebo, there was also no significant change in pulmonary function with salmeterol. Veale et $\mathrm{al}^{26}$ also noted no significant change in sleep quality or nocturnal oxygenation after using the long-acting beta2-agonist salbutamol for 7 days as compared to placebo in 11 patients with COPD. Again, there was no significant change in spirometry when compared to placebo. More recently, Budhiraja et $\mathrm{l}^{6}$ reported a lower prevalence of insomnia in those COPD patients who were using the beta-agonists albuterol and formoterol.

Regarding the effects of inhaled anticholinergics on sleep quality in patients with COPD, Martin et $\mathrm{al}^{32}$ examined the effects of 4 weeks of ipratropium bromide compared to placebo on sleep quality and pulmonary function in 36 patients with COPD. Compared to placebo, the ipratropium bromide group demonstrated an increase in pre-sleep FVC and flow rate at $50 \%$ of vital capacity. For sleep quality, the ipratropium bromide group demonstrated an improvement in perceived sleep quality, and an increase in REM time and mean $\mathrm{SaO}_{2}$ during the night but no change in total sleep time. McNicholas et al ${ }^{28}$ studied the effects of 4 weeks of inhaled tiotropium on spirometry and sleep quality in 56 patients with COPD. While there was an improvement in spirometry and $\mathrm{SaO}_{2}$ during the night in the tiotropium group as compared to the placebo group, there was no change in sleep quality. The effects of theophylline on sleep quality and pulmonary function in COPD patients has also been examined, with the majority of studies demonstrating an improvement in spirometry and nocturnal oxygenation, but no change or a worsening in sleep quality. ${ }^{23-25,27}$ In the present study, there was a significant increase in spirometry in the budesonideformoterol-tiotropium group but not in the placebotiotropium group at the end of 28 days. While there was no change in both objective and subjective sleep quality in the budesonide-formoterol-tiotropium group, there was a significant increase in the arousal index and ESS noted in the placebo-tiotropium group. However, the initial difference in the ESS scores in the budesonide-formoterol-tiotropium group and the placebo-tiotropium group (6 [3-8, 0-11] and 8 [5-12, 2-18], respectively) may lessen the clinical significance of the increase in the ESS noted in the placebo-tiotropium group. In addition, there were more female participants in the placebo-tiotropium group (61\%) than in the budesonide-formoteroltiotropium group (40\%) which may have affected our results. However, while female patients with COPD have been noted to have lower QoL scores than men, 50 improvements in response to combination therapy as it relates to pre-treatment $\mathrm{FEV}_{1}$, exacerbation rates, and QOL appear to be similar between genders. ${ }^{51}$ Furthermore, in participants without OSA, similar to our patients, women and men have been shown to have similar ESS scores. ${ }^{52}$ 
Prior studies demonstrating an improvement in sleep quality with the use of nocturnal non-invasive ventilation or following lung volume reduction surgery in patients with COPD have suggested that a change in respiratory mechanics was responsible. ${ }^{20,21}$ In the present study, the significant increase in bedtime $\mathrm{FEV}_{1}$ in the triple therapy group is probably related to a decrease in air trapping. However, whether an associated improvement in respiratory mechanics contributed to the preserved sleep quality in the budesonide-formoterol-tiotropium group was not evaluated.

Our study showed no change in QoL scores for both the budesonide-formoterol-tiotropium group as well as the placebo-tiotropium group as measured using the SF 36 and disease specific SGRQ-C scores. While prior studies using triple therapy have shown improvements in QOL scores, patients were treated over longer periods of time, anywhere from 12 weeks to as long as 1 year. ${ }^{33-42}$

There are some limitations with the study that need to be addressed. First, the number of patients enrolled and who completed the study (23 patients) was small. However, it is similar to other studies which have evaluated the effects of inhaled bronchodilator medications on sleep quality and nocturnal oxygenation in patients with COPD. ${ }^{26,31,32}$ Second, the duration of the study at 28 days was relatively short. Although an improvement in spirometry was noted in the budesonide-formoteroltiotropium group, the effects on sleep quality and QoL may require a longer period of time on therapy. The time period is similar to other studies evaluating the effects of inhaled bronchodilator medications in these patients. ${ }^{28,31,32}$

In conclusion, we demonstrated that compared to placebo-tiotropium, 28 days of the inhaled triple therapy of budesonide-formoterol-tiotropium improved pulmonary function and preserved sleep quality in patients with GOLD stage 2 and 3 COPD. Whether more prolonged use would lead to similar or more substantial effects on sleep quality awaits further investigation.

\section{Acknowledgements}

Author Contributions: SLK takes responsibility for the study as a whole. MEV, JD, HP, FJ, GED, WC, YMD, SC, XS, SW and GJC contributed to study design, data collection, data analysis, statistical analysis and manuscript preparation. TS contributed to polysomnogram data collection and scoring. DY contributed to the data analysis, statistical analysis and manuscript preparation.

\section{Declaration of Interests}

The authors report no conflict of interest related to the publication of this paper. 


\section{References}

1. Cormick W, Olson LG, Hensley MJ, Suadners NA. Nocturnal hypoxaemia and quality of sleep in patients with chronic obstructive lung disease. Thorax. 1986; 41(11):846-854.

doi: https://doi.org/ 10.1136/thx.41.11.846

2. Klink ME, Dodge R, Quan SF. The relation of sleep complaints to respiratory symptoms in the general population. Chest. 1994;105(1):151-154.

doi: https://doi.org/10.1378/chest.105.1.151

3. Dodge R, Cline MG, Quan SF. The natural history of insomnia and its relationship to respiratory symptoms. Arch Intern Med. 1995;155(16):1797-1800.

doi: https://doi.org/10.1001/archinte.1995.00430160145014

4. Bellia V, Catalano F, Scichilone N, et al. Sleep disorders in the elderly with and without chronic airflow obstruction: the SARA study. Sleep. 2003;26(3):318-323.

doi: https://doi.org/10.1093/sleep/26.3.318

5. Budhiraja R, Roth T, Hudgel DW, Budhiraja P, Drake CL. Prevalence and polysomnographic correlates of insomnia comorbid with medical disorders. Sleep. 2001; 34(7):859-867. doi: https://doi.org/10.5665/SLEEP.1114

6. Budhiraja R, Parthasarathy S, Budhiraja P, Habib MP, Wendel C, Quan SF. Insomnia in patients with COPD. Sleep. 2012;35(3):369375. doi: https://doi.org/10.5665/sleep.1698

7. Calverley PMA, Brezinova V, Douglas NJ, Catterall JR, Flenley DC. The effect of oxygenation on sleep quality in chronic bronchitis and emphysema. Am Rev Respir Dis. 1982; 126(2):206-210.

8. Fleetham J, West P, Mezon B, Conway W, Roth T, Kryger M. Sleep, arousals, and oxygen desaturation in chronic obstructive pulmonary disease: the effect of oxygen therapy. Am Rev Respir Dis. 1982;126(3):429-433.

9. Wynne JW, Block AJ, Hemenway J, Hunt LA, Flick MR. Disordered breathing and oxygen desaturation during sleep in patients with chronic obstructive lung disease. Am J Med. 1979; 66(4):573-579. doi: https://doi.org/10.1016/0002-9343(79)91166-5

10. Krachman SL, Chatila W, Martin UJ, et al. Physiologic correlates of sleep quality in severe emphysema. COPD. 2011;8(3):182-188. doi: https://doi.org/10.3109/15412555.2011.560583

11. Nunes DM, Mota RM, de Pontes Neto OL, Pereira ED, de Bruin VM, de Bruin PF. Impaired sleep reduces quality of life in chronic obstructive pulmonary disease. Lung. 2009;187:159-163.

doi: https://doi.org/10.1007/s00408-009-9147-5

12. Omachi TA, Blanc PD, Claman DM, et al. Disturbed sleep among COPD patients is longitudinally associated with mortality and adverse COPD outcomes. Sleep Med. 2102;13:476-483. doi: https://doi.org/10.1016/j.sleep.2011.12.007
13. Fletcher EC, Miller J, Divine GW, Fletcher JG, Miller T. Nocturnal oxyhemoglobin desaturation in COPD patients with arterial oxygen tensions above $60 \mathrm{mmHg}$. Chest. 1987;92(4):604-608. doi: https://doi.org/10.1378/chest.92.4.604

14. Lewis CA, Fergusson W, Eaton T, Zeng I, Kolbe J. Isolated nocturnal desaturation in COPD: prevalence and impact on quality of life and sleep. Thorax. 2009;64(2):133-138.

doi: https://doi.org/10.1136/thx.2007.088930

15. Sica AL, Greenberg HE, Ruggiero DA, Scharf SM. Chronic-intermittent hypoxia: a model of sympathetic activation in the rat. Respir Physiol. 2000;121(2-3):173-184. doi: https://doi.org/10.1016/S0034-5687(00)00126-2

16. Gilmartin GS, Lynch M, Tamisier R, Weiss JW. Chronic intermittent hypoxia in humans during 28 nights results in blood pressure elevation and increased muscle sympathetic nerve activity. Am J Physiol Heart Circ Physiol. 2010;299(3):H925-931. doi: https://doi.org/10.1152/ajpheart.00253.2009

17. McKeon JL, Murree-Allen K, Saunders NA. Supplemental oxygen and quality of sleep in patient with chronic obstructive lung disease. Thorax. 1989;44(3):184-188. doi: https://doi.org/10.1136/thx.44.3.184

18. Goldstein RS, Ramcharan V, Bowes G, McNicholas WT, Bradley D, Phillipson EA. Effect of supplemental nocturnal oxygen on gas exchange in patients with severe obstructive lung disease. $N$ Engl $J$ Med. 1984;310:425-429.

doi: https://doi.org/10.1056/NEJM198402163100704

19. Bratel T, Wennlung A, Carlstrom K. Impact of hypoxaemia on neuroendocrine function and catecholamine secretion in chronic obstructive pulmonary disease (COPD). Effects of long-term oxygen treatment. Respir Med. 2000; 94:1221-1228.

doi: https://doi.org/10.1053/rmed.2000.0953

20. Krachman SL, Chatila W, Martin UJ, et al. Effects of lung volume reduction surgery on sleep quality and nocturnal gas exchange in patients with severe emphysema. Chest. 2005;128(5):3221-3228. doi: https://doi.org/10.1378/chest.128.5.3221

21. Krachman SL, Quaranta AJ, Berger TJ, Criner GJ. Effects of noninvasive positive pressure ventilation on gas exchange and sleep in COPD patients. Chest. 1997;112(3):623-628. doi: https://doi.org/10.1378/chest.112.3.623

22. Kwon JS, Wolfe LF, Lu BS, Kalhan R. Hyperinflation is associated with lower sleep efficiency in COPD with co-existent obstructive sleep apnea. COPD. 2009;6(6):441-445. doi: https://doi.org/10.3109/15412550903433000

23. Martin RJ, Pak J. Overnight theophylline concentrations and effects on sleep and lung function in chronic obstructive pulmonary disease. Am Rev Respir Dis. 1992;145(3):540-544.

doi: https://doi.org/10.1164/ajrccm/145.3.540 
24. Berry RB, Desa MM, Branum JP, Light RW. Effect of theophylline on sleep and sleep-disordered breathing in patients with chronic obstructive pulmonary disease. Am Rev Respir Dis. 1991;143(2):245250. doi: https://doi.org/10.1164/ajrccm/143.2.245

25. Mulloy E, McNicholas WT. Theophylline improves gas exchange during rest, exercise and sleep in severe chronic obstructive pulmonary disease. Am Rev Respir Dis. 1993;148(4pt1):1030-1036. doi: https://doi.org/10.1164/ajrccm/148.4_Pt_1.1030

26. Veale D, Cooper BG, Griffiths CJ, Corris PA, Gibson GJ. The effect of controlled-release salbutamol on sleep and nocturnal oxygenation in patients with asthma and chronic obstructive pulmonary disease. Resp Med. 1994;88(2):121-124.

doi: https://doi.org/10.1016/0954-6111(94)90023-X

27. Man GCW, Chapman KR, Ali SH, Darke AC. Sleep quality and nocturnal respiratory function with once-daily theophylline (Uniphyl) and inhaled salbutamol in patients with COPD. Chest. 1996;110(3):648-653. doi: https://doi.org/10.1378/chest.110.3.648

28. McNicholas WT, Calverley PM, Lee A, Edwards JC. Long-acting inhaled anticholinergic therapy improves sleeping oxygen saturation in COPD. Eur Respir J. 2004;23(6):825-831.

doi: https://doi.org/10.1183/09031936.04.00085804

29. Brander PE, Salmi T. Nocturnal oxygen saturation and sleep quality in patients with advanced chronic obstructive pulmonary disease during treatment with moderate dose CR-theophylline. Eur J Clin Pharmacol. 1992;43(2):125-129. doi: https://doi.org/10.1007/BF01740657

30. Series F, Cormier Y. Effects of protriptyline on diurnal and nocturnal oxygenation in patients with chronic obstructive pulmonary disease. Ann Intern Med. 1990;113:507-511.

doi: https://doi.org/10.7326/0003-4819-113-7-507

31. Ryan S, Doherty LS, Rock C, Nolan GM, McNicholas WT. Effects of salmeterol on sleeping oxygen saturation in chronic obstructive pulmonary disease. Respiration. 2010;79:475-481. doi: https://doi.org/10.1159/000235619

32. Martin RJ, Bucher Bartelson B, Smith P, et al. Effect of ipatropium bromide treatment on oxygen saturation and sleep quality in COPD. Chest. 1999;115(5):1338-1345.

doi: https://doi.org/10.1378/chest.115.5.1338

33. Aaron SD, Vandemheen KL, Fergusson D, et al. Tiotroium in combination with placebo, salmeterol, or fluticasone-salmeterol for treatment of chronic obstructive pulmonary disease: a randomized trial. Ann Intern Med. 2007;146:545-555.

doi: https://doi.org/ 10.7326/0003-4819-146-8-200704170-00152

34. Welte T, Miravitlles, Hernandez P, et al. Efficacy and tolerability of budesonide/formoterol added to tiotropium in patient with chronic obstructive pulmonary disease. Am J Respir Crit Care Med. 2009;180(8):741-750.

doi: https://doi.org/10.1164/rccm.200904-0492OC
35. Short PM, Williamson PA, Elder DHJ, Lipworth SIW, Schembri S, Lipworth BJ. The Impact of tiotropium on mortality and exacerbations when added to inhaled corticosteroids and long-acting B-agonist therapy in COPD. Chest. 2102;141(1):81-86. doi: https://doi.org/10.1378/chest.11-0038

36. Firth PA, Thompson PJ, Ratnavadivel R, et al. Glycopyrronium oncedaily significantly improves lung function and health status when combined with salmeterol/fluticasone in patients with COPD: the GLISTEN study - a randomised controlled trial. Thorax. 2015; 70:519527. doi: https://doi.org/10.1136/thoraxjnl-2014-206670

37. Singh D, Papi A, Corradi M, et al. Single inhaler triple therapy versus inhaled corticosteroid plus long-acting B2-agonist therapy for chronic obstructive pulmonary disease (Trilogy): a double-blind, parallel group, randomised controlled trial. Lancet. 2016;388(10048):963-973. doi: https://doi.org/10.1016/S0140-6736(16)31354-X

38. Lipson DA, Barnacle H, Birk R, et al. FULFIL trial: once-daily triple therapy for patients with chronic obstructive pulmonary disease. Am J Respir Crit Care Med. 2017;196(4):438-446. doi: https://doi.org/10.1164/rccm.201703-0449OC

39. Vestbo J, Papi A, Corradi M, et al. Single inhaler extrafine triple therapy versus long-acting muscarinic antagonist therapy for chronic obstructive pulmonary disease (TRINITY): a double-blind, parallel group, randomised controlled trial. Lancet. 2017;389(10082):19191929.

doi: https://doi.org/10.1016/S0140-6736(17)30188-5

40. Lipson DA, Barnhart F, Brealey N, et al. Once-daily single-inhaler triple versus dual therapy in patients with COPD. $N$ Engl $J$ Med. 2018;378:1671-80.

doi: https://doi.org/10.1056/NEJMoa1713901

41. Ferguson GT, Rabe KF, Martinez FJ, et al. Triple therapy with budesonide/glycopyrrolate/formoterol fumarate with co-suspension delivery technology versus dual therapies with chronic obstructive pulmonary disease(KRONOS): a double-blind, parallel-group, multicenter, phase 3 randomised controlled trial. Lancet Respir Med. 2018;6(10):747-758.

doi: https://doi.org/10.1016/S2213-2600(18)30327-8

42. Papi A, Vestbo J, Fabbri L, et al. Extrfine inhaled triple therapy versus dual bronchodilator therapy in chronic obstructive pulmonary disease (TRIBUTE): a double-blind, parallel group, randomised controlled trial. Lancet. 2018;391(10125):1076-84. doi: https://doi.org/10.1016/S0140-6736(18)30206-X

43. Global Initiative for Chronic Obstructive Lung Disease (GOLD). Global strategy for the diagnosis, management, and prevention of COPD, 2020 report. GOLD website. https://www.goldcopd.org. Published December 2019. Accessed July 2020.

44. Berry RB, Brooks R, Gamaldo CE, Harding SM, Vaughn BV; for the American Academy of Sleep Medicine (AASM). The AASM manual for the scoring of sleep and associated events: rules, terminology and technical specifications, Version 2.0. ASSM website. Published 2012. Accessed July 2020. www.aasmnet.org 
45. Miller MR, Hankinson J, Brusasco V, et al. Standardisation of spirometry. Eur Respir J. 2005; 26(2):319-338. doi: https://doi.org/10.1183/09031936.05.00034805

46. Johns MW. A new method for measuring daytime sleepiness: the Epworth sleepiness scale. Sleep. 1991;14(6):540-545. doi: https://doi.org/10.1093/sleep/14.6.540

47. Monk TH, Berman SR, Kupfer DJ. The Pittsburgh sleep quality index: a new instrument for the psychiatric practice and research. Psych Res. 1989;28(2):193-213. doi: https://doi.org/10.1016/0165-1781(89)90047-4

48. Jones PW, Quirk FH, Baveystock CM, Littlejohns P. A self-complete measure of health status for chronic airflow limitation. The St George's Respiratory Questionnaire. Am Rev Respir Dis. 1992;145(6):13211327. doi: https://doi.org/10.1164/ajrccm/145.6.1321

49. Ware JE, Sherbourne CD. The MOS 36-item short-form health survey (SF-36). I. Conceptual framework and item selection. Med Care. 1992;30(6):473-483.

doi: https://doi.org/10.1097/00005650-199206000-00002

50. de Torres JP, Casanova C, Hernández C, Abreu J, Aguirre-Jaime A, Celli BR. Gender and COPD in patients attending pulmonary clinic. Chest. 2005;128(4):2012-2016.

doi: https://doi.org/10.1378/chest.128.4.2012

51. Vestbo J, Soriano JB, Anderson JA, Calverley P, Pauwels R, Jones P. Gender does not influence the response to the combination of salmeterol and fluticasone propionate in COPD. Respir Med. 2004;98(11):1045-1050.

doi: https://doi.org/10.1016/j.rmed.2004.03.017

52. Eliasson AH , Kashani MD, Howard RS, Vernalis MN, Modlin RE, Integrative Cardiac Health Project Registry. Fatigued on Venus, sleepy on Mars - gender and racial differences in symptoms of sleep apnea. Sleep Breath. 2015;19(1):99-107.

doi: https://doi.org/10.1007/s11325-014-0968-y 